Article

\title{
Recovery of Molybdenum Precursor Material in the Cyclotron-Based Technetium-99m Production Cycle
}

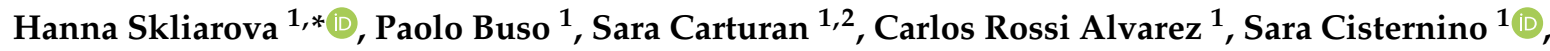 \\ Petra Martini ${ }^{1,3} \mathbb{D}$, Alessandra Boschi ${ }^{3}$ and Juan Esposito ${ }^{1}(\mathbb{B}$ \\ 1 Legnaro National Laboratories, Italian National Institute for Nuclear Physics (LNL-INFN), Viale \\ dell’Università, 35020 Legnaro, Italy; paolo.buso@lnl.infn.it (P.B.) Sara.Carturan@lnl.infn.it (S.C.); \\ Carlos.Rossi.Alvarez@lnl.infn.it (C.R.A.); Sara.Cisternino@lnl.infn.it (S.C.); petra.martini@lnl.infn.it (P.M.); \\ Juan.Esposito@lnl.infn.it (J.E.) \\ 2 Department of Physics and Astronomy, University of Padua, 35121 Padua, Italy \\ 3 Department of Morphology, Surgery and Experimental Medicine, University of Ferrara, 44121 Ferrara, Italy; \\ bsclsn@unife.it \\ * Correspondence: Hanna.Skliarova@lnl.infn.it; Tel.: +39-049-806-8416
}

Received: 22 December 2018; Accepted: 5 February 2019; Published: 13 February 2019

\begin{abstract}
A closed-loop technology aiming at recycling the highly ${ }^{100}$ Mo-enriched molybdenum target material has been developed in the framework of the international research efforts on the alternative, cyclotron-based ${ }^{99 \mathrm{~m}} \mathrm{Tc}$ radionuclide production. The main procedure steps include (i) ${ }^{100} \mathrm{Mo}$-based target manufacturing; (ii) irradiation under proton beam; (iii) dissolution of ${ }^{100} \mathrm{Mo}$ layer containing ${ }^{9 \times}$ Tc radionuclides (produced by opened nuclear reaction routes) in concentrated $\mathrm{H}_{2} \mathrm{O}_{2}$ solution; and (iv) Mo/Tc separation by the developed radiochemical module, from which the original ${ }^{100}$ Mo comes as the "waste" alkaline aqueous fraction. Conversion of the residual ${ }^{100} \mathrm{Mo}$ molybdates in this fraction into molybdic acids and $\mathrm{MoO}_{3}$ has been pursued by refluxing in excess of $\mathrm{HNO}_{3}$. After evaporation of the solvent to dryness, the molybdic acids and $\mathrm{MoO}_{3}$ may be isolated from $\mathrm{NaNO}_{3}$ by exploiting their different solubility in water. When dried in vacuum at $40{ }^{\circ} \mathrm{C}$, the combined aqueous fractions provided $\mathrm{MoO}_{3}$ as a white powder. In the last recovery step $\mathrm{MoO}_{3}$ has been reduced using a temperature-controlled reactor under hydrogen overpressure. An overall recovery yield of $\sim 90 \%$ has been established.
\end{abstract}

Keywords: radioisotope production; Molybdenum-100; cyclotron; molybdenum material recovery

\section{Introduction}

${ }^{99 \mathrm{~m}} \mathrm{Tc}$ is a radionuclide widely used in Conventional Nuclear Medicine diagnostic examinations. It is routinely eluted from portable generators containing the parent radionuclide ${ }^{99} \mathrm{Mo}$, coming from highly-enriched (>80 wt.\% ${ }^{235} \mathrm{U}$ ) uranium targets irradiated in nuclear fission reactors. Once separated from the ${ }^{235} \mathrm{U}$ fission products and further purified, ${ }^{99} \mathrm{Mo}$ is loaded onto an alumina column inside the portable generator. ${ }^{99 \mathrm{~m}}$ Tc-radiopharmaceuticals are then directly prepared in hospital radiopharmacies by adding the ${ }^{99 \mathrm{~m}}$ Tc-pertechnetate eluted from generators directly in lyophilized "kits", following the manufacturer instructions and quality control specifications to get an injectable product. Approximately $95 \%$ of the world's production of ${ }^{99} \mathrm{Mo}$ is provided by few ageing nuclear reactors, whose unplanned outages have already caused global shortages in the last decade, even recently (November 2018) [1]. In order to mitigate this problem in the mid-long term, alternative ${ }^{99 \mathrm{~m}} \mathrm{Tc}$ production routes have been intensively investigated all over the world.

A dedicated CRP (Coordinated Research Project) program launched by the International Atomic Energy Agency (IAEA) in 2011-2015 [2,3] was dedicated to the ${ }^{99 \mathrm{~m}} \mathrm{Tc} /{ }^{99}$ Mo accelerator-based 
production routes. Main CRP outcomes have revealed that the direct ${ }^{99 \mathrm{~m}} \mathrm{Tc}$ production, through the ${ }^{100} \mathrm{Mo}(\mathrm{p}, 2 \mathrm{n})$ nuclear reaction, starting from highly ${ }^{100} \mathrm{Mo}$-enriched (i.e., enrichment $>99.5 \%$ ) molybdenum targets is the most promising approach [3-7]. In this context, the optimal proton energy range $10-25 \mathrm{MeV}$, able to provide sufficient amounts of the radioisotope with impurity level within the limits defined by corresponding European Pharmacopeia [8], has been identified [6,9]. Furthermore, recommended target thickness and irradiation times for optimized production at different irradiation energies (15, 20 and $25 \mathrm{MeV}$ ) have been calculated by Esposito et al. (2013) [10].

The purpose of the TECHnetium direct-production in hOSPital (TECHN-OSP) research project at INFN $[4,10-12]$ was the development of a technology able to produce GBq amounts of ${ }^{99 \mathrm{~m}}$ Tc through the $(\mathrm{p}, 2 \mathrm{n})$ nuclear reaction route on ${ }^{100} \mathrm{Mo}$-enriched metal targets. This approach could provide the daily routine supply by exploiting the existing medical cyclotron network in Italy.

A cyclotron-based ${ }^{99} \mathrm{~m}$ Tc closed-loop production cycle includes the following steps, as shown in Figure 1. (i) ${ }^{100}$ Mo target manufacturing, (ii) target irradiation with a proton cyclotron, (iii) dissolution of ${ }^{100}$ Mo layer containing ${ }^{9 x} \mathrm{Tc}$ radionuclides (plus $\mathrm{Nb}, \mathrm{Zr}$ impurities) in the concentrated $\mathrm{H}_{2} \mathrm{O}_{2}$ solution, (iv) separation/purification of ${ }^{99 \mathrm{~m}} \mathrm{Tc}$ from ${ }^{100} \mathrm{Mo}$ and by-products by a developed dedicated separation module, and (v) recovery of the costly ${ }^{100}$ Mo material remaining as the "waste" after the separation procedure $[4,12]$.

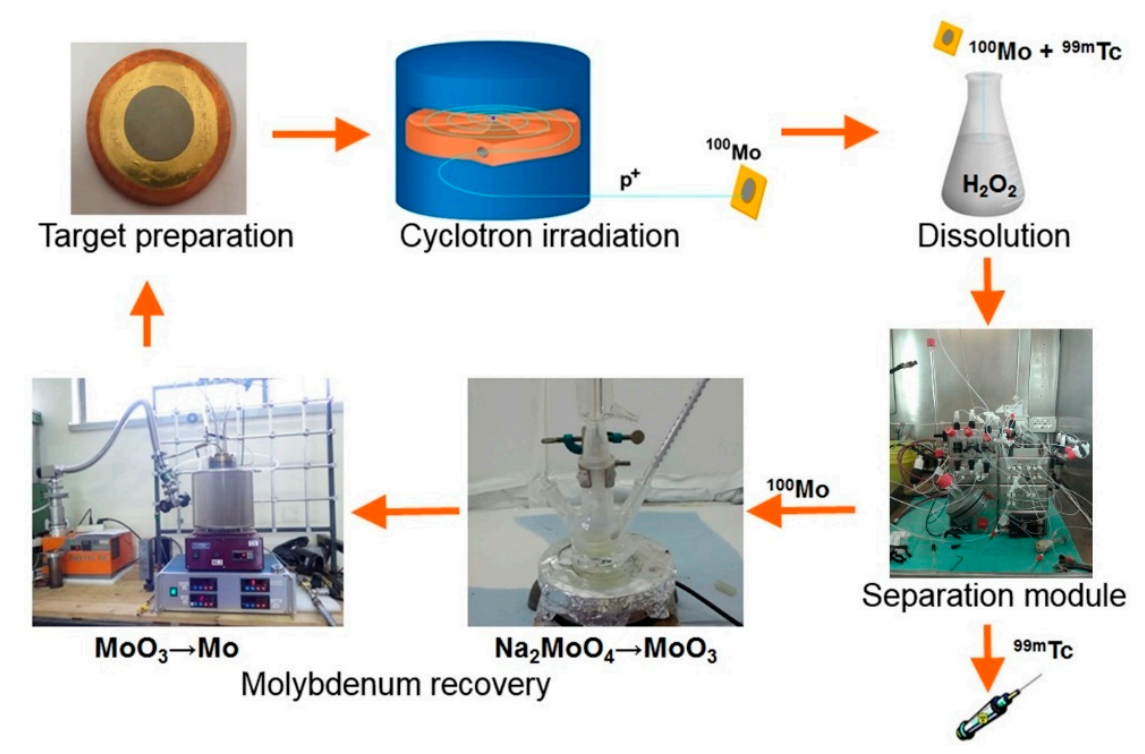

Figure 1. TECHnetium direct-production in hOSPital (TECHN-OSP) ${ }^{99 \mathrm{~m}}$ Tc production cycle.

As regards the ${ }^{100} \mathrm{Mo}$ metal target, several configurations have been developed and tested in the framework of the TECHN-OSP project:

- Mo-sputtered layer onto a complex backing plate (patent PCT/IB2018/056826) [13,14].

- HIVIPP (HIgh energy VIbrational Powders Plating) electrostatic deposition [15] of Mo onto metallic backing with a high yield deposition efficiency ( $>95 \%)$ and uniformity, but limited thickness $(2-3 \mu \mathrm{m})$.

- $\quad$ Stacked-foils clamped into a dedicated target holder.

- Spark Plasma Sintering (SPS) of ${ }^{100}$ Mo powders onto an inert backing plate.

In order to meet the requirements for a fast and efficient dissolution, extraction and purification of ${ }^{99 \mathrm{~m}}$ Tc yielded from ${ }^{100}$ Mo-enriched molybdenum metallic target irradiation, a remotely controlled module based on the Solvent Extraction (SE) technique has been developed. After the irradiation, the targets were processed according to a protocol presented in Figure 2 and described in details by Martini et al. [12]. All quality control procedures on the final products, radiolabeling, in vivo and on phantom imaging studies with a clinical gamma camera, have been conducted as well [16]. 


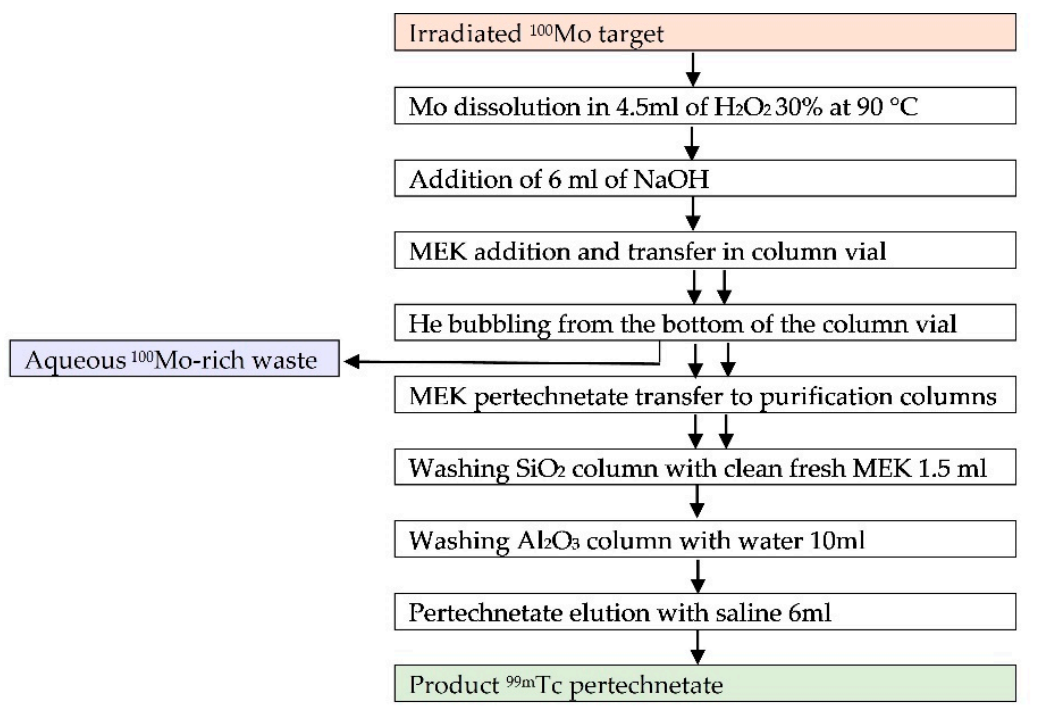

Figure 2. Target processing and ${ }^{100} \mathrm{Mo} /{ }^{99 \mathrm{~m}} \mathrm{Tc}$ separation-purification protocol.

In order to make the cyclotron-based ${ }^{99} \mathrm{~m} \mathrm{Tc}$ production costs affordable, the expensive ${ }^{100} \mathrm{Mo}$-enriched material should be recovered from the separation module waste with the aim to be reused for the preparation of new targets, thus closing the production cycle.

Therefore, the goal of this work was to develop a molybdenum material recovery procedure under metallic form, starting from the isotope-rich "waste" fraction from the dedicated separation module [4,12], which has been cited as the most efficient among the ones reviewed in the work by Gumiela et al. [17]. We applied a two-step procedure, which consists of the conversion of sodium molybdates present in the waste fraction into $\mathrm{MoO}_{3}$, then followed by further reduction of molybdenum oxide into metallic molybdenum.

\section{Materials and Methods}

In order to simulate the Mo-rich waste coming from the radiochemical separation module [12], $304.2 \pm 3.3 \mathrm{mg}$ of natural Mo (100 $\mu \mathrm{m}$ thickness foils, $99.95 \%$ purity purchased from Advent Research Materials Ltd., Eynsham, Oxford, England) went through the automatic radiochemical processing as described in Figure 2. Briefly, molybdenum was dissolved in $4.5 \mathrm{~mL} 30 \% \mathrm{H}_{2} \mathrm{O}_{2}$ at $90{ }^{\circ} \mathrm{C}$ in $\sim 30$ min; then $6 \mathrm{~mL}$ of $6 \mathrm{M} \mathrm{NaOH}$ were added to the solution, and the same procedure applied in the case of SE of technetium from the solution was repeated twice using methyl ethyl ketone (MEK) [12]. The residual aqueous Mo-rich solution, containing molybdate and polymolybdate species, was stored in glass vials, and water was removed by evaporation just before using it for the recovery studies. The residue was then washed with ethanol, filtered and dried at room temperature obtaining $0.79 \pm$ $0.18 \mathrm{~g}$ of precipitate. In the following sections, it will be mentioned as molybdates mixture.

\section{1. $\mathrm{MoO}_{3}$ Recovery from Mo-Rich Module "Waste"}

The first step of molybdenum recovery is the conversion of sodium molybdates mixture to molybdic acid and $\mathrm{MoO}_{3}$. The experiment has been performed using Mo-rich "waste" coming from the separation module [12], standard chemical glassware, and commercially available chemical compounds: $\mathrm{HCl}, 37 \%$, p.a. grade, Aldrich (Darmstadt, Germany); $\mathrm{HNO}_{3}, 65 \%$, p.a. grade, Sigma Aldrich S.r.l. (Milan, Italy); and $\mathrm{NH}_{4} \mathrm{OH}, 30 \%$, p.a. grade, Carlo Erba (Cornaredo, Italy).

In order to achieve the highest recovery yield and purity, different techniques were tested (recipes $1-4)$ as described in the following section. The main approach used for $\mathrm{MoO}_{3}$ recovery is known as the Mo-based "spent catalyst regeneration" procedures. Two methods were proposed by Park [18] (Figure 3a) and Kar [19] (Figure 3b). In both processes, the key steps interesting for the present recovery study, start from the conversion of ammonium molybdate in $\mathrm{MoCl}_{6}$ by $\mathrm{HCl}$ treatment (step 
4 on Figure $3 a$ and steps 7 and 12 on Figure $3 b$ ). Then, ammonium hydroxide at controlled $\mathrm{pH}$ is added in order to obtain ammonium molybdate (step 5 on Figure 3a and steps 8 and 14 on Figure 3b). Afterwards, ammonium molybdate is precipitated by varying the solution $\mathrm{pH}$ (step 6 on Figure 3a and step 15 on Figure $3 b$ ) and calcinated at $450{ }^{\circ} \mathrm{C}$ to finally produce the pure $\mathrm{MoO}_{3}$ product (step 7 on Figure $3 a$ and steps 9 and 16 on Figure $3 b)$.

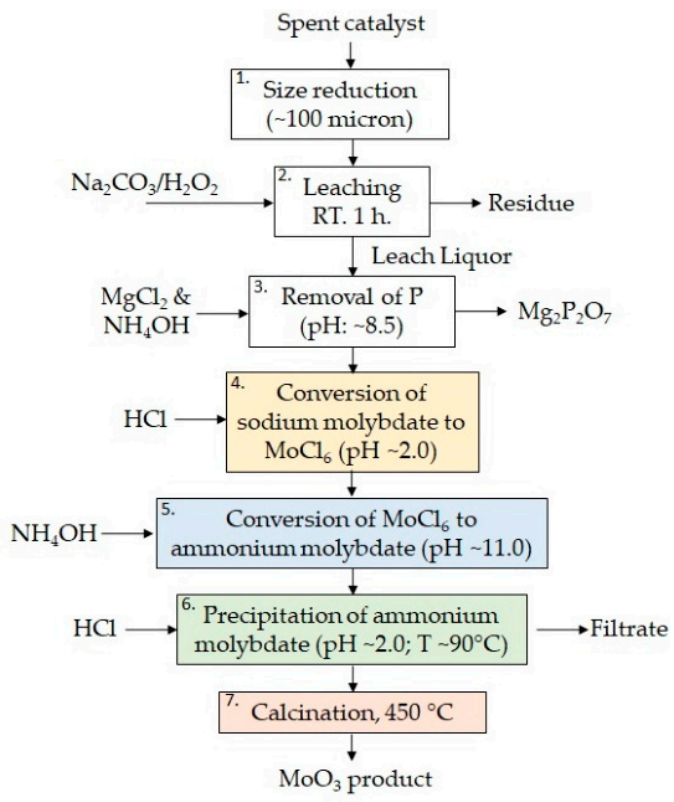

(a)

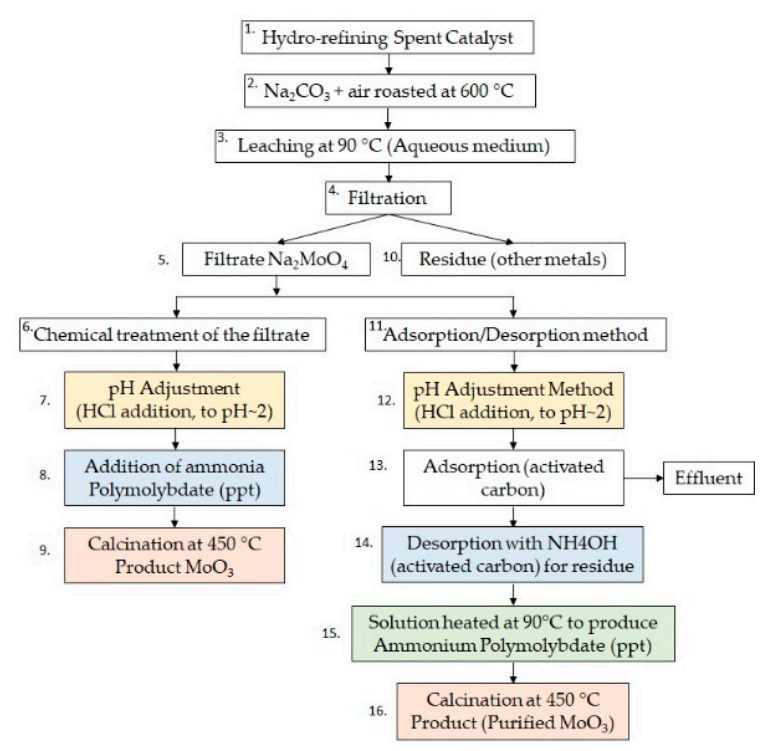

(b)

Figure 3. $\mathrm{MoO}_{3}$ recovery as regeneration of a spent catalyst described by Park [18] (a) and Kar [19] (b).

\subsubsection{Spent Catalyst Approach}

Recipe $\mathrm{MoO}_{3}-1$. Into $\sim 0.5 \mathrm{~g}$ of the dry Mo-rich "waste" coming from the separation module, $15 \mathrm{~mL}$ of $0.1 \mathrm{M}$ hydrochloric acid were added. The solution became yellow as a result of $\mathrm{MoCl}_{6}$ production at $\mathrm{pH}=2$. Then, $50 \mathrm{~mL}$ of $1 \mathrm{M} \mathrm{NH}_{4} \mathrm{OH}$ were added to the solution, and the color turned blue/transparent at $\mathrm{pH}=10.6$. After heating the solution to $80^{\circ} \mathrm{C}$, the $\mathrm{pH}$ was observed to decrease to 9.5 , owing to ammonia release. The precipitate was centrifuged for $8 \mathrm{~min}$, recovered, and finally dried in vacuum overnight at $40^{\circ} \mathrm{C}$. The weight of the obtained pale yellow powder was $0.4 \mathrm{~g}$.

\subsubsection{Spent Catalyst Approach, Nitric Acid}

Recipe $\mathrm{MoO}_{3}-2$. Into $\sim 0.5 \mathrm{~g}$ of the product coming from the separation module $2-3 \mathrm{~mL}$ of $5 \mathrm{M}$ $\mathrm{HNO}_{3}$ and $10 \mathrm{~mL}$ of deionized water were added. The solution became yellow at $\mathrm{pH}=0$ (lower limit of $\mathrm{pH}$-meter). Then, concentrated $\mathrm{NH}_{4} \mathrm{OH}$ was added dropwise to the solution until $\mathrm{pH}=2$, and the color turned yellow-green. The last drop of ammonium hydroxide changed the $\mathrm{pH}$ to 5.3 (desired $\mathrm{pH}$ $=2.5-3$ ). The solution became pale blue after heating at $80^{\circ} \mathrm{C}$ for $2 \mathrm{~h}$ and precipitation of white flakes occurred. The precipitate was centrifuged for $8 \mathrm{~min}$, washed twice with $10 \mathrm{~mL}$ of ethanol, and dried in vacuum overnight at $40{ }^{\circ} \mathrm{C}$. The weight of the obtained white powder was $0.11 \mathrm{~g}$.

\subsubsection{Direct Precipitation with Nitric Acid}

Recipe $\mathrm{MoO}_{3}-3$. Into $\sim 0.13 \mathrm{~g}$ of the product coming from the separation module $3-5 \mathrm{~mL}$ of $5 \mathrm{M}$ $\mathrm{HNO}_{3}$ (excess) were added. The mixture was heated up in reflux mode at $95^{\circ} \mathrm{C}$ for $7 \mathrm{~h}$. Then, the liquid was evaporated and the solid was washed twice with $15 \mathrm{~mL}$ of a mixture of $\mathrm{EtOH}: \mathrm{H}_{2} \mathrm{O}$ (3:1 volumetric), prior to centrifugation at $4000 \mathrm{rpm}$ for $8 \mathrm{~min}$. The precipitate was dried in vacuum overnight at $40{ }^{\circ} \mathrm{C}$, giving $0.082 \mathrm{~g}$ of white powder. 
Recipe $\mathrm{MoO}_{3}$-4. $0.7 \mathrm{~g}{ }^{\text {nat }} \mathrm{Mo}$ foil of $250 \mu \mathrm{m}$ thick (99.99\% purity, Goodfellow, Cambridge Ltd., Huntingdon, England) was dissolved in $15 \mathrm{~mL}$ of $30 \% \mathrm{H}_{2} \mathrm{O}_{2}$ at $90{ }^{\circ} \mathrm{C}$. The dissolution went on for 20 min. When the solution was cooled down to $50{ }^{\circ} \mathrm{C}, 5 \mathrm{~mL}$ of $6 \mathrm{M} \mathrm{NaOH}$ was added to the solution and it was maintained for $30 \mathrm{~min}$ in order to simulate the process in a module. Hence, $25 \mathrm{~mL}$ of $5 \mathrm{M} \mathrm{HNO}_{3}$ (excess) was added to the solution. The mixture was heated up in reflux mode at $95^{\circ} \mathrm{C}$ overnight. After evaporation, a white precipitate was obtained and washed with several portions of distilled water $(15 \mathrm{~mL}, 3 \times 7.5 \mathrm{~mL})$. Then, the precipitate was dried in vacuum overnight at $40{ }^{\circ} \mathrm{C}$ giving 0.986 $\mathrm{g}$ of white powder.

\section{2. $\mathrm{MoO}_{3}$ Reduction System}

The second step of the closed-loop technology (i.e., the enriched molybdenum recovery process) is the molybdenum oxide reduction to metal, as described above. It was carried out using a dedicated hydrogenation reactor system. The apparatus is schematized in Figure $4 \mathrm{a}$ and it is composed of a vacuum system, a furnace, a tungsten reduction cell filled with hydrogen, a liquid nitrogen Dewar, and a process data acquisition system.

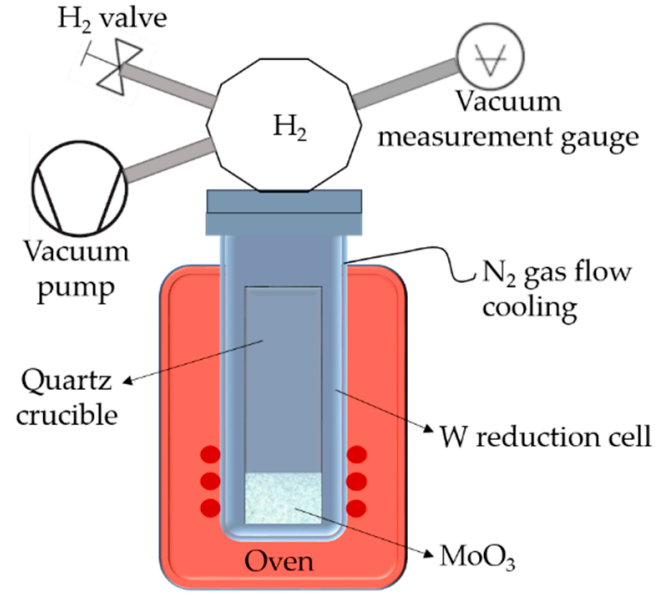

(a)

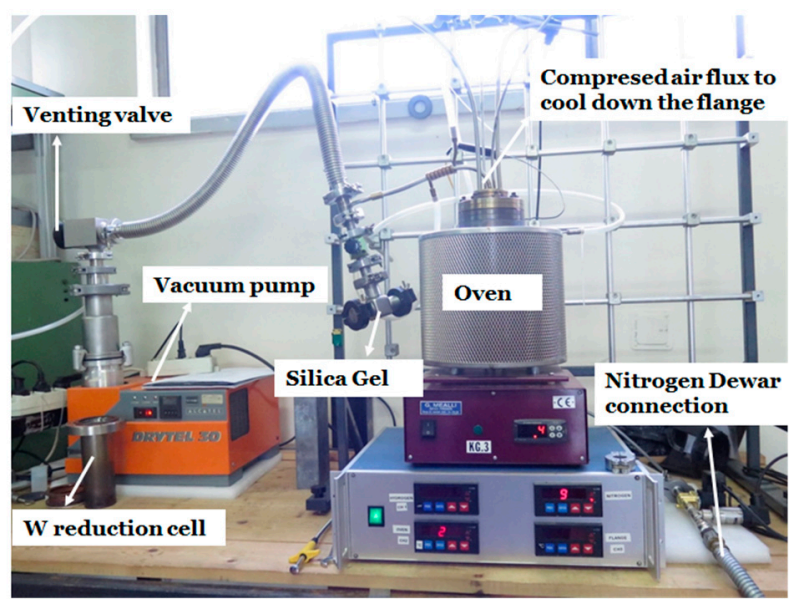

(b)

Figure 4. Reduction system scheme (a) and the laboratory prototype (b).

While other groups have used laboratory-scale hydrogenation systems [20] where the reduction process requires a constant hydrogen flow (i.e., an open system), in the present work we applied a different recovery method, using a batch overpressure reactor (i.e., a closed system). This approach has been chosen to fulfil safety regulations operating at LNL. Moreover, it is expected to be effective since the amount of oxide to be treated is lower with respect to the experiments presented by other groups. In order to shift the equilibrium towards the products in the chemical reaction, two techniques were simultaneously used: (i) carrying out the experiment in a hydrogen overpressure condition and (ii) condensing and capturing the water released during reduction by an appropriate amount of silica gel. Therefore, the reduction capability of the system depends on the maximum amount of hydrogen that can be inserted in safety conditions and on the water adsorption capability of the dried silica gel trap.

The full reduction system prototype developed in present work is schematically shown in Figure $4 \mathrm{~b}$. During reduction experiments, $\mathrm{MoO}_{3}$ was placed in a quartz crucible inside the tungsten reduction reactor with the total volume (including the volume inside the tubes before the valves) of $\sim 1.2 \mathrm{~L}$. The system was pumped down to remove air, and then hydrogen in overpressure was inserted by the gas valve.

The resistive furnace was used to heat up the reduction cell. Nitrogen gas released from the liquid nitrogen $\left(\mathrm{LN}_{2}\right)$ Dewar was used for cooling down both the tube to condensate the water produced during the reaction and the tungsten reduction cell external walls. The nitrogen flux valve opened 
automatically when the oven temperature exceeded $250{ }^{\circ} \mathrm{C}$. Silica gel $(\sim 10 \mathrm{~g})$ was placed in a box inside the vacuum system for trapping the produced water. Compressed air was used to cool down the flange that closes the reduction cell on the top.

The Alcatel Drytel 30 (Anaheim, CA, USA) oil-free multistage high vacuum pumping system composed of a $7.5 \mathrm{~L} / \mathrm{s}$ turbo drag pump and a $1 \mathrm{~m}^{3} / \mathrm{h}$ diaphragm pump was used for preliminary evacuation of the reduction cell. The Drytel 30 can operate from atmosphere to $\sim 1 \times 10^{-6}$ mbar, with a maximum pumping speed of $16 \mathrm{cfm}\left(\sim 27 \mathrm{~m}^{3} / \mathrm{h}\right)$ in the high vacuum range.

The $1400 \mathrm{~W}$ resistive melting furnace (Giuseppe Mealli S.r.l., Firenze, Italy) was used as a heating source for the reduction process. It is equipped with Kanthal (Hallstahammar, Sweden) resistors to ensure high temperatures and long duration. The thermal insulation is made of ceramic fiber in order to achieve rapid heating in combination with low power consumption. The oven can reach a maximum temperature of $1150^{\circ} \mathrm{C}$.

The reduction reactor was realized in a tungsten-copper-sintered composite material allowing to combine the high melting temperature of tungsten with the good machinability of copper. Nitrogen gas flow was passing around the external walls of the reduction cell in order to minimize its oxidation at elevated temperatures.

The main parameters controlled during the process included

- $\quad$ oven temperature $\left(0-1100^{\circ} \mathrm{C}\right)$;

- $\quad$ flange temperature $\left(0-500{ }^{\circ} \mathrm{C}\right)$;

- hydrogen pressure (0-8000 mbar absolute);

- nitrogen pressure (2-2000 mbar absolute).

A dedicated program written in Java language (version 1.7) was used to control the reduction system. It allowed to set up the multistep heating process. The heating parameters are shown in Table 1.

Table 1. Heating parameters for reduction control.

\begin{tabular}{ccc}
\hline Step & Temperature Range $\left({ }^{\circ} \mathbf{C}\right)$ & Programmed Temperature Rate $\left({ }^{\circ} / \mathbf{m i n}\right)$ \\
\hline 1 & Room temperature-350 & 5 \\
2 & $350-750$ & 2 \\
3 & $750-950$ & 5 \\
4 & 950 & Constant for $\mathrm{X} h$ \\
5 & 950 -room temperature & Natural convection cooling \\
\hline
\end{tabular}

In step four, the temperature was kept constant for $\mathrm{X}$ hours, depending on the starting amount of $\mathrm{MoO}_{3}$. The heating parameters were modified, directly by the user during the process, through the GUI (graphical user interface). In case of emergency, a button allowed to immediately stop the process. If the flange temperature exceeds $350^{\circ} \mathrm{C}$, the program interrupts the process and the cooling starts.

The maximum amount of $\mathrm{MoO}_{3}$ powder that can be reduced using $2500 \mathrm{mbar}_{2}(270 \mathrm{mg})$ is $2.7 \mathrm{~g}$ (18 mmol). In this case, the amount of $\mathrm{H}_{2}$ used for reduction is $108 \mathrm{mg}$. When the process is finished, $\mathrm{H}_{2}$ final pressure of 1500 mbar ( 1685 mbar theoretical) is obtained, thus maintaining the requirement of overpressure. The increase of the $\mathrm{MoO}_{3}$ load is possible: in this case, the volume of the apparatus should be increased proportionally in order to maintain the corresponding hydrogen overpressure after the reduction. It should be also taken into account that the maximum pressure achieved inside the new apparatus during the process has to be controlled for the safety issue.

\subsection{Analysis of the Products}

The applied analytical techniques to characterize the recovery and reduction products comprised $\mathrm{X}$-ray diffraction (XRD) and scanning electron microscopy equipped with energy-dispersive spectroscopy (EDS-SEM). 
XRD analysis has been performed with X'Pert Philips PW3040/60 diffractometer equipped with $1.54 \AA \mathrm{Cu}-\mathrm{K} \alpha \mathrm{X}$-ray in $\theta / \theta$ scanning mode. The scans were taken at $40 \mathrm{kV}, 40 \mathrm{~mA}$ of $\mathrm{Cu}-\mathrm{K} \alpha \mathrm{X}$-ray gun. The PW3071/xx Bracket sample stage was used in reflection mode.

For powders analysis, previously grinded in agate mortar Si zero-background sample holder was used. A semiquantitative analysis with X'Pert HighScore software was applied without any additional calibration. The outcome of XRD analysis is supported and completed by SEM-EDS investigation in order to fully investigate both crystalline and amorphous phases. Moreover, the results in terms of structure, composition and quantification have been compared with those expected from the involved chemical reactions.

Fei (former Philips) Scanning Electron Microscope SEM XL-30 equipped with the QUATNTAX energy-dispersive X-ray spectrometer of BRUKER (Billerica, Massachusetts, United States) were used for analysis of powders. It should be mentioned that the inaccuracy of the quantitative elemental analysis by EDX method is not less than 5\% [21].

Furthermore, the quantification due to mass change can be considered the most precise quantification method, provided an evidence that the set of the reactions and the products has been correctly identified. For the reduction of $\mathrm{MoO}_{3}$, it was considered that the products could contain $\mathrm{Mo}$ and $\mathrm{MoO}_{2}$ also on the basis of previous literature data [20,22]. Thus, only two possible reactions were taken into account:

$$
\begin{aligned}
& \mathrm{MoO}_{3}+3 \mathrm{H}_{2}=\mathrm{Mo}+3 \mathrm{H}_{2} \mathrm{O} \\
& \mathrm{MoO}_{3}+\mathrm{H}_{2}=\mathrm{MoO}_{2}+\mathrm{H}_{2} \mathrm{O}
\end{aligned}
$$

In order to know the correct mass of the precursor, $\mathrm{MoO}_{3}$ was baked in the vacuum oven to remove water traces before weighing.

\section{Results and Discussion}

\section{1. $\mathrm{MoO}_{3}$ Recovery from Mo-Rich Separation Module "Waste"}

The starting material for the recovery procedure developed in the present study was coming from the separation module treatment of natural molybdenum foils. The module and the dissolution procedures are described in details by Martini et al. [12]. According to the EDS analysis of the dried Mo-rich "waste" fraction from the module, it contained mainly $\mathrm{Mo}, \mathrm{Na}$, and $\mathrm{O}$, with a huge excess of $\mathrm{Na}$ in respect to Mo. According to the XRD analysis, the mixture contained sodium molybdate $\mathrm{Na}_{2} \mathrm{MoO}_{4}$, disodium dimolybdate $\mathrm{Na}_{2} \mathrm{Mo}_{2} \mathrm{O}_{7}$, sodium tetramolybdenum hexoxide $\mathrm{NaMo}_{4} \mathrm{O}_{6}$, and sodium peroxide $\mathrm{Na}_{2} \mathrm{O}_{2}$ (from partial conversion of sodium hydroxide $\mathrm{NaOH}$ ).

Following the literature approach called "spent catalyst regeneration" (see Recipe $\mathrm{MoO}_{3}-1$ ) a white-yellowish powder was obtained, containing $\mathrm{Mo}, \mathrm{Na}, \mathrm{O}, \mathrm{N}$, and $\mathrm{Cl}$ according to EDS analysis. Hence, we can suggest that $\mathrm{MoCl}_{6}, \mathrm{Na}_{2} \mathrm{MoO}_{4}\left(\mathrm{H}_{2} \mathrm{O}\right)_{\mathrm{x}}$, and $\left(\mathrm{NH}_{4}\right)_{2} \mathrm{MoO}_{4}\left(\mathrm{H}_{2} \mathrm{O}\right)_{\mathrm{y}}$ were present on the basis of starting reagents and chemical reactions involved. Thus, the applied procedure appeared to be not efficient to transform all sodium molybdate from the mixture coming from the separation module into ammonium molybdate.

In order to minimize the amount of $\mathrm{MoCl}_{6}$ impurity, hydrochloric acid was replaced by nitric acid (see Recipe $\mathrm{MoO}_{3}-2$ ). According to EDS analysis, 2\% Na and $~ 11 \%$ Mo were still detected in the product. Thus, the second method also did not provide the full conversion of sodium molybdate into ammonium molybdate as expected.

The last method proposed here, described in Scheme (3), included a direct conversion to molybdenum oxide and molybdic acids, thus skipping the ammonium molybdate step (see Recipe $\left.\mathrm{MoO}_{3}-3\right)$. 


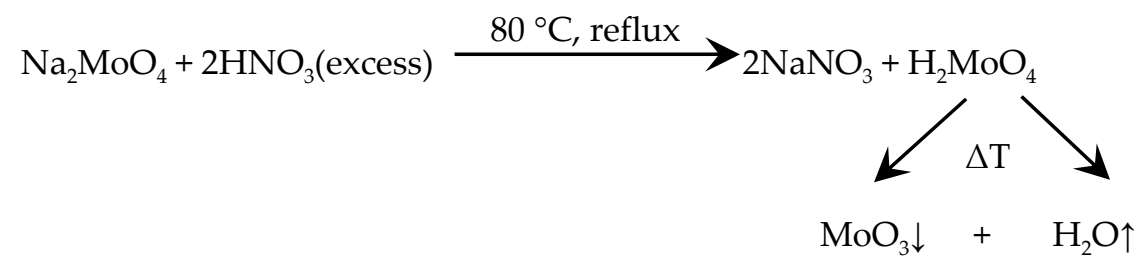

After precipitation, molybdic acids and sodium nitrate were separated on the basis of different water solubility [23]. Then, the solid was dried in a vacuum and analyzed by EDS and XRD. The structural analysis confirmed the presence of $\mathrm{MoO}_{3}$ and $\mathrm{Na}_{2} \mathrm{MoO}_{4}$, while the EDS analysis led to quantify $0.3 \% \mathrm{Na}$ and $15 \% \mathrm{Mo}$, thereby suggesting an enhanced separation efficiency with respect to previous experiments.

Furthermore, it has to be noted that Si impurity was detected in all the products coming from the separation module. It was supposed that $\mathrm{Si}$ impurity was produced by storing the product (Mo-rich waste from separation module) in glass vessels for several months' (simulating the way to operate with enriched material). In fact, sodium molybdate fraction has a high concentration of residual sodium hydroxide, thus, glass corrosion is likely to occur. It is worth to highlight that for the repeated cycles of recovery the absence of the impurities is a crucial factor. In particular, in the case of irradiation of recovered Mo with traces of $\mathrm{Si}$ at $10-25 \mathrm{MeV}$ a set of undesired reaction channels can be opened. In order to avoid the described problem and unambiguously identify the source of $\mathrm{Si}$ the process of dissolution was reproduced starting from ${ }^{\text {nat }} \mathrm{Mo}$ foil (see Recipe $\mathrm{MoO}_{3}-4$ ), avoiding the storage in a glass vessel and realizing the recovery procedure immediately after the reproduced dissolution procedure. Two tests have been performed in parallel using in one case standard chemical glassware and in the other case Teflon labware. In both cases, Si impurity was not detected by EDS. This experiment unambiguously demonstrated, that silicon came from the glass vials corroded during the long term storage of the highly basic Mo-rich "waste" and that this contamination can be easily avoided.

It was found that the most efficient method to recover $\mathrm{MoO}_{3}$ from the $\mathrm{NaOH}$-rich waste of the ${ }^{100} \mathrm{Mo} /{ }^{99} \mathrm{~m}$ Tc-separation module is the one reported as Recipe $\mathrm{MoO}_{3}-4$. Possible products are $\mathrm{Na}_{2} \mathrm{MoO}_{4}, \mathrm{NaNO}_{3}$, and $\mathrm{MoO}_{3}$. The same atomic content of $\mathrm{Na}$ and $\mathrm{N}$ was observed by EDS. Thus, $\mathrm{Na}_{2} \mathrm{MoO}_{4}$ should not be present any more in the mixture. In this case, the product contains $\mathrm{MoO}_{3}$ with few $\mathrm{NaNO}_{3}$ and, as expected, without any Si impurity. According to EDS analysis, Na impurity was present in $\sim 3 \%$ at., (or recalculated $\sim 2 \%$ weight $\mathrm{NaNO}_{3}$ ) in $\mathrm{MoO}_{3}$ product. This method allows to remove $\mathrm{Na}$ and leads to a $\mathrm{MoO}_{3}$ yield of $\sim 92 \%$, which can be further improved by optimizing the precipitate washing conditions or using an ion exchange resin.

\section{2. $\mathrm{MoO}_{3}$ Reduction to Mo Metallic}

The reduction of molybdenum (VI) oxide is realized in two steps:

$$
\begin{gathered}
\mathrm{MoO}_{3}(\mathrm{~s})+\mathrm{H}_{2}(\mathrm{~g}) \rightarrow \mathrm{MoO}_{2}(\mathrm{~s})+\mathrm{H}_{2} \mathrm{O}(\mathrm{g}) \\
\log \mathrm{K}_{(4)}=4469.7 / \mathrm{T}+1.27 \\
\mathrm{MoO}_{2}(\mathrm{~s})+2 \mathrm{H}_{2}(\mathrm{~g}) \rightarrow \mathrm{Mo}(\mathrm{s})+2 \mathrm{H}_{2} \mathrm{O}(\mathrm{g}) \\
\log \mathrm{K}_{(5)}=-4363.9 / \mathrm{T}+2.87
\end{gathered}
$$

The first step of the conversion (Equation (4)) is exothermic and thermodynamically favorable at $550-600{ }^{\circ} \mathrm{C}[24,25]$. The exothermic reaction can cause local overheating and $\mathrm{MoO}_{3}$ volatilization. This aspect limits the velocity of heating. On the other hand, the second step (Equation (5)) is endothermic, and relatively high temperature and $\mathrm{H}_{2} / \mathrm{H}_{2} \mathrm{O}$ ratio higher than two are required to achieve hydrogen reduction of $\mathrm{MoO}_{2}$. According to the literature [24], the temperature necessary to carry on the second stage of the reduction can be varied in the range from $930^{\circ} \mathrm{C}$ to $1000{ }^{\circ} \mathrm{C}$ depending upon the desired 
Mo powder size. The lower the reduction temperature, the smaller the reduced Mo powder size. However, for low reduction temperatures, a longer reduction time is required in order to achieve a complete conversion [24]. The detailed description of the kinetics of the second step can be found in the work by Kim et al. [26].

The procedure for reduction under $\mathrm{H}_{2}$ gas flow and the 3-step conversion starting from ammonium molybdate were described by Gupta [27] for nonenriched isotopes and by Gagnon et al. for enriched elements recovery [20]. Here, the reduction from $\mathrm{MoO}_{3}$ to $\mathrm{MoO}_{2}$ was considered to be completed at $500-750{ }^{\circ} \mathrm{C}$ keeping the heating rate at $2{ }^{\circ} \mathrm{C} / \mathrm{min}$, and the further reduction to metallic Mo was performed at $750-1100{ }^{\circ} \mathrm{C}$ with heating rate $5{ }^{\circ} \mathrm{C} / \mathrm{min}$ and reduction time of $1 \mathrm{~h}$ at maximum temperature. An overall Mo recovery of $87 \%$ was reported [20].

The reduction thermal cycle optimized in the current work is presented in Figure 5. The heating velocity of $5{ }^{\circ} \mathrm{C} / \mathrm{min}$ was used up to $450{ }^{\circ} \mathrm{C}$, then the heating velocity was decreased to $2{ }^{\circ} \mathrm{C} / \mathrm{min}$ until the temperature of $750{ }^{\circ} \mathrm{C}$ was reached. In this temperature range, the conversion to $\mathrm{MoO}_{2}$ takes place. A lower heating ramp was used to minimize the sublimation of $\mathrm{MoO}_{3}$, induced by local overheating caused by the exothermic reaction. The heating from $750{ }^{\circ} \mathrm{C}$ to $950{ }^{\circ} \mathrm{C}$ was realized with a $5{ }^{\circ} \mathrm{C} / \mathrm{min}$ ramp rate. Then, the reduction from $\mathrm{MoO}_{2}$ to Mo was performed at $950{ }^{\circ} \mathrm{C}$, setting different time intervals for each experiment, as listed in Table 2. Subsequent cooldown was obtained through natural convection, simply by switching off the furnace. The product was exposed to air only after the system had reached the room temperature.

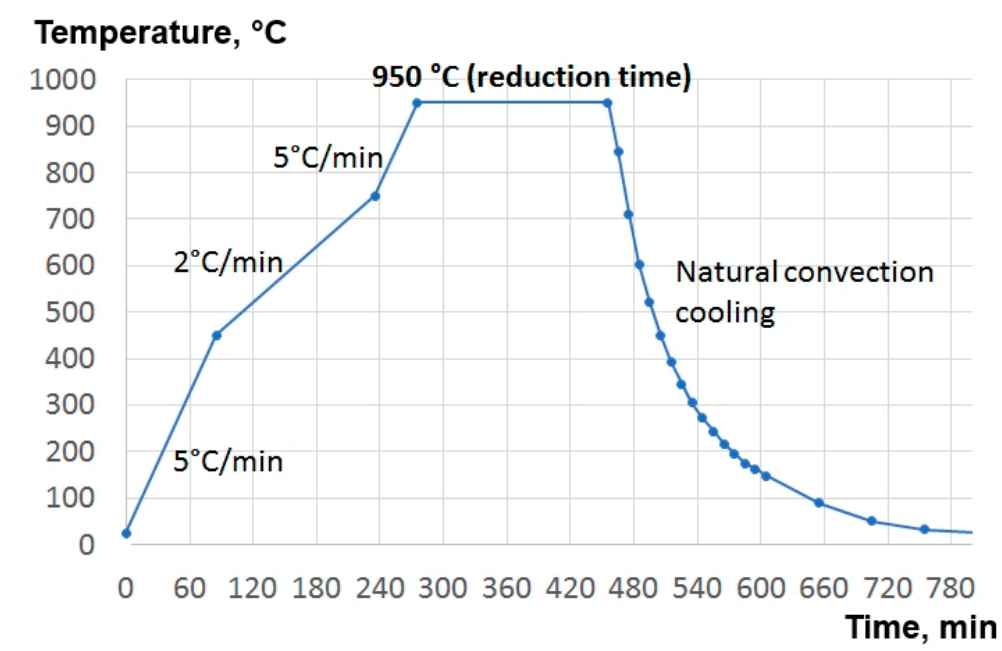

Figure 5. The optimized $\mathrm{MoO}_{3}$ reduction thermal cycle.

Table 2. $\mathrm{MoO}_{3}$ reduction experiments.

\begin{tabular}{|c|c|c|c|c|c|c|c|}
\hline \multirow{2}{*}{ Red. exp-t } & \multirow{2}{*}{$\mathrm{MoO}_{3}$ Origin } & \multirow{2}{*}{$\begin{array}{c}\mathrm{MoO}_{3} \\
\text { Mass }\end{array}$} & \multirow{2}{*}{$\begin{array}{l}\text { Red. } \\
\text { Time }\end{array}$} & \multirow{2}{*}{$\begin{array}{l}\text { Product } \\
\text { Mass }\end{array}$} & \multicolumn{3}{|c|}{ Product Content, Mass \% } \\
\hline & & & & & Mo & $\mathrm{MoO}_{2}$ & Impurities \\
\hline R-1 & Alfa Aesar & $587 \mathrm{mg}$ & $1 \mathrm{~h}$ & $500 \mathrm{mg}$ & $\sim 12 \%$ & $\sim 88 \%$ & $C(<1 \%)$ \\
\hline $\mathrm{R}-2$ & Alfa Aesar & $389 \mathrm{mg}$ & $6 \mathrm{~h}$ & $261 \mathrm{mg}$ & $\sim 98 \%$ & $<2 \%$ & $C(<1 \%)$ \\
\hline $\mathrm{R}-3.1$ & Alfa Aesar & $1 \mathrm{~g}$ & $1.5 \mathrm{~h}$ & $864 \mathrm{mg}$ & $\sim 15 \%$ & $\sim 85 \%$ & $C(<1 \%)$ \\
\hline $\mathrm{R}-3.2$ & Product of R-3.1 & $864 \mathrm{mg}$ & $2 \mathrm{~h}$ & $687 \mathrm{mg}$ & $>90 \%$ & $>2 \%$ & $C(<2 \%)$ \\
\hline $\mathrm{R}-4$ & Product of rec. $\mathrm{MoO}_{3}-2$ & $61 \mathrm{mg}$ & $2 \mathrm{~h}$ & $37 \mathrm{mg}$ & $\sim 90 \%$ & - & $\mathrm{SiO}_{2}(\sim 9 \%)+\mathrm{Na}_{2} \mathrm{SiO}_{3}(<1 \%)$ \\
\hline R-5 & Product of rec. $\mathrm{MoO}_{3}-3$ & $49 \mathrm{mg}$ & $2 \mathrm{~h}$ & $34 \mathrm{mg}$ & $>95 \%$ & - & $\mathrm{SiO}_{2}(<2 \%)$ \\
\hline
\end{tabular}

\subsubsection{Reduction of Commercial $\mathrm{MoO}_{3}$}

In order to develop the reduction method, commercially available $\mathrm{MoO}_{3}$ powders from Sigma Aldrich were used. The grain size of the powders was $<5 \mu \mathrm{m}$.

The parameters and the results of the reduction experiments are listed in Table 2. The first reduction experiment $\mathrm{R}-1$, starting from $\sim 0.6 \mathrm{~g}$ of commercial $\mathrm{MoO}_{3}$, was realized with just $1 \mathrm{~h}$ reduction time at $950{ }^{\circ} \mathrm{C}$. According to the results of the analyses $(\mathrm{XRD}, \mathrm{EDS}$, and quantification 
based on the mass of the product), this time was not sufficient to convert all $\mathrm{MoO}_{3}$ into metallic Mo. Nevertheless, no $\mathrm{MoO}_{3}$ was detected in the final product by XRD, thus indicating that the first step of the process (Equation (4)) was completed.

Increasing the reduction time to $6 \mathrm{~h}$ in the following experiment $\mathrm{R}-2$ allowed us to obtain more than $95 \%$ of Mo metallic starting from $\sim 0.4 \mathrm{~g}$ of commercial $\mathrm{MoO}_{3}$ (Table 2). According to EDS analysis, still a few $\%$ of $\mathrm{MoO}_{2}$ remained unreduced. The yield of the reaction is $\sim 98 \%$. It should be said, that it was possible to distinguish even visually the products $\mathrm{R}-1$ rich of hygroscopic $\mathrm{MoO}_{2}$ (see Figure 6a) and the R-2 product containing almost only metallic Mo powders (Figure 6b). The XRD spectra, normalized on the intensity of the most intense peaks, obtained from the reduction products are shown in Figure 7.

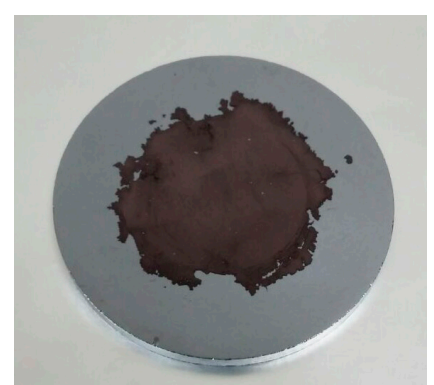

(a)

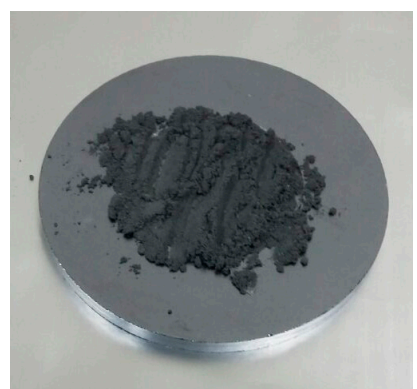

(b)

Figure 6. $\mathrm{MoO}_{3}$ reduction products: R-1 hygroscopic powder rich of $\mathrm{MoO}_{2}$ (a) and R-2 almost only Mo metallic (b).

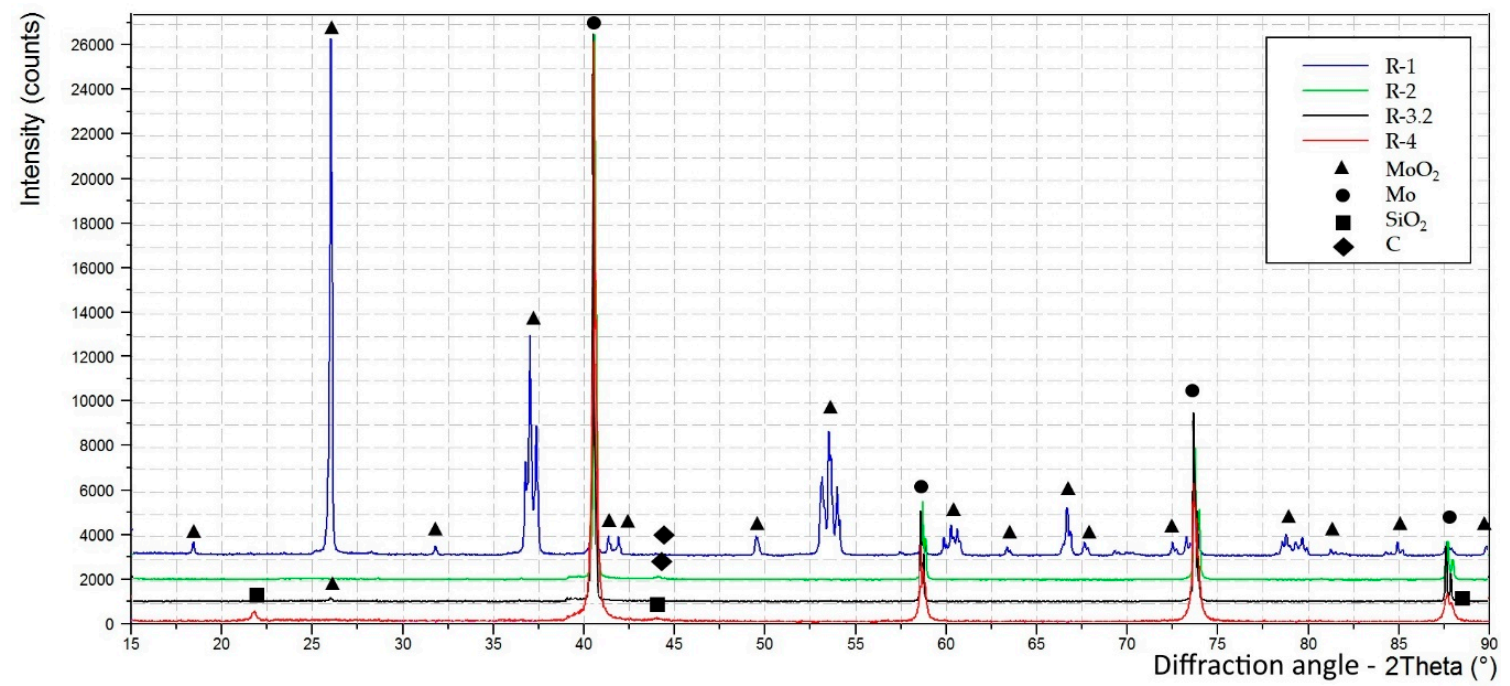

Figure 7. X-ray diffraction (XRD) spectra of the products of different reduction experiments.

The next experiment, with a higher amount of starting $\mathrm{MoO}_{3}$, was realized in two steps. The R-3.1 during $1.5 \mathrm{~h}$ of reduction allowed to get only $\sim 10 \%$ of Mo metallic (see Table 2 ). In order to convert more than $90 \%$ of molybdenum oxide to Mo metallic (Table 2), the additional $2 \mathrm{~h}$ of reduction were required (R-3.2).

Some carbon-based impurities were detected in the product by XRD (see Figure 7), probably related to previous heating of a graphite crucible in the same furnace. In order to avoid such contamination in the future, the tungsten reactor was mechanically polished.

The reduced molybdenum powders are characterized by the grain size of about $1 \mu \mathrm{m}$ and display nonspherical, slightly irregular shape. The SEM analysis of the products of the reduction R-2 and R-3 is shown in Figure 8. 


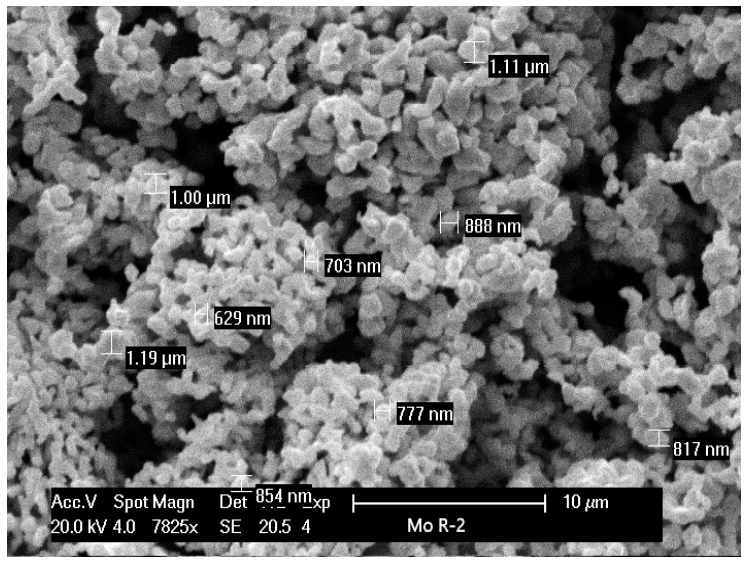

(a)

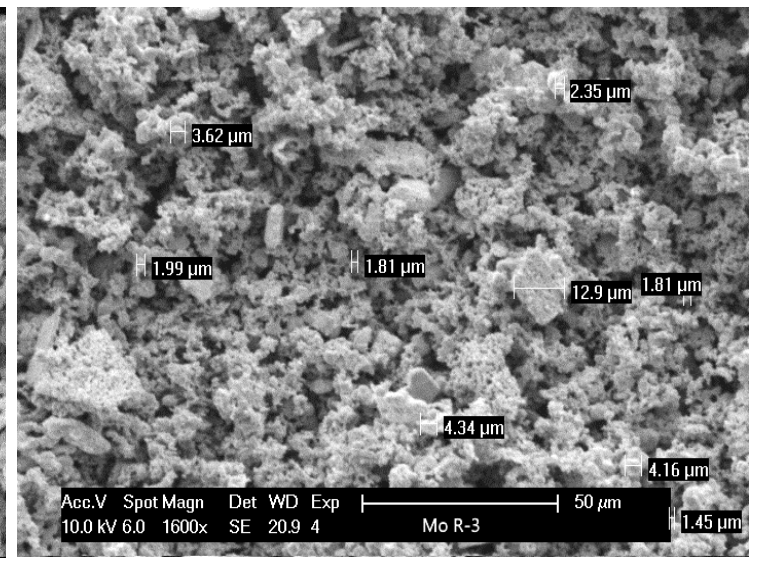

(b)

Figure 8. SEM of the products of reduction R-2 (a) and R-3.2 (b).

\subsubsection{Reduction of Recovered $\mathrm{MoO}_{3}$}

Several reduction experiments starting from $\mathrm{MoO}_{3}$ recovered from the module Mo-rich waste were realized. It should be taken into account that the precursor $\left(\mathrm{MoO}_{3}\right.$ from the recovery procedure) was not as pure as the commercial $\mathrm{MoO}_{3}$.

From the analysis of the $\mathrm{MoO}_{3}$ precursor coming from the recovery procedure, it was evident that it contained the impurities of glass $\mathrm{SiO}_{2}$ and $\mathrm{Na}_{2} \mathrm{SiO}_{3}$. From the reduction product analysis (Table 2), it can be seen that the glass contaminants remained, when $\mathrm{MoO}_{3}$ was reduced to Mo metallic. $\mathrm{Na}_{2} \mathrm{SiO}_{3}$ was not detected by XRD, owing to its amorphous nature. The quantification on the basis of reaction stoichiometry calculations is not reliable because of the glass contaminants. Nevertheless, since no $\mathrm{MoO}_{2}$ was detected by XRD (see Figure 7), the reduction of $\mathrm{MoO}_{3}$ could be considered complete.

Similarly to what observed in the previous experiment, the $\mathrm{SiO}_{2}$ impurity coming from the $\mathrm{MoO}_{3}$ recovered from the separation module waste remained in the product (Table 2). The appearance of the product was very similar to the R-2 metallic powders (see Figure 9a). From Figure 9b, showing the EDS mapping of the reduction product, it can be clearly observed that oxygen is associated with Si to form $\mathrm{SiO}_{2}$. Moreover, according to EDS elemental analysis, the ratio between the atomic composition of $\mathrm{Si}$ and $\mathrm{O}$ is 1:2, thus indicating that all oxygen is associated with $\mathrm{Si}$, and there is no excess oxygen to form molybdenum oxide. Therefore, the complete transformation of $\mathrm{MoO}_{3}$ was demonstrated by the absence of $\mathrm{MoO}_{2}$ in the product. For both experiments R-4 and R-5, two hours at $950{ }^{\circ} \mathrm{C}$ was sufficient to complete the reduction of $\sim 50 \mathrm{mg} \mathrm{MoO}$ to Mo metallic.

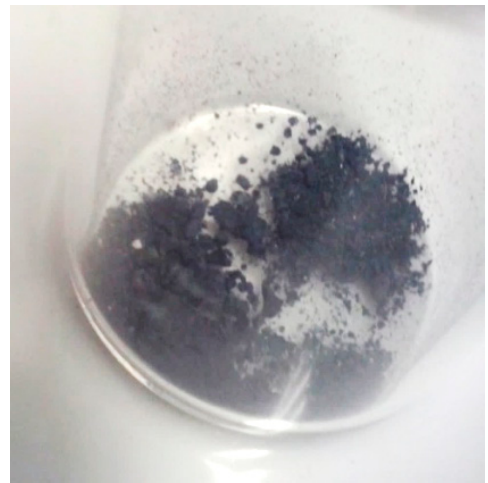

(a)

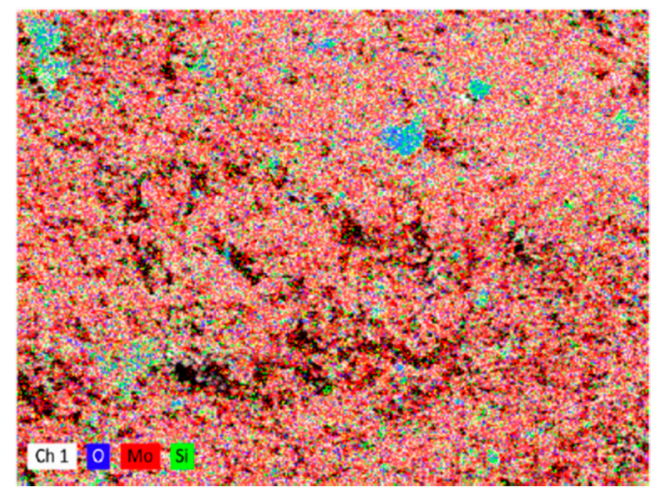

(b)

Figure 9. R-5 $\mathrm{MoO}_{3}$ reduction product (a) and its energy-dispersive spectroscopy (EDS) map analysis (b). 
The developed method allows for the recovery of Mo in metallic form, starting from the Mo-rich "waste" coming from the radiochemical separation module, in two steps with yields of approximately $92 \%$ and $98 \%$, respectively, ultimately leading to the overall yield of more than $90 \%$.

\subsubsection{Recovered Mo Applicability for Further Cyclotron Target Preparation}

Among the Mo cyclotron solid target preparation methods developed in TECHN-OSP project, the reduced Mo powders have been successfully tested only for electrostatic deposition (HIVIPP) technique. Mo target with $\sim 3-\mu \mathrm{m}$ thickness deposited by HIVIPP technique onto aluminium backing starting from reduced Mo powders coming from the experiment R-2 is shown in Figure 10a.

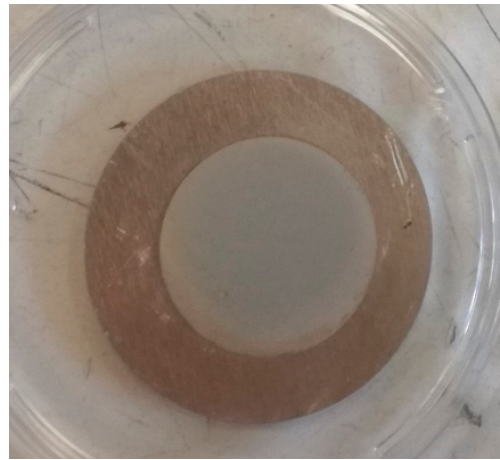

(a)

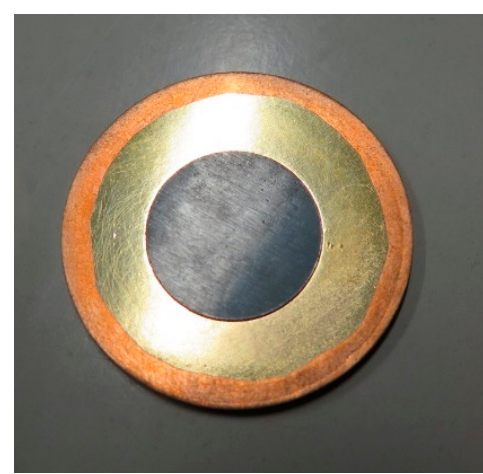

(b)

Figure 10. Mo targets prepared with high energy vibrational powders plating (HIVIPP) method starting from reduced powders (a) and spark plasma sintering (SPS)-sintered target from ${ }^{100} \mathrm{Mo}$ of Isoflex (b).

From SEM analysis it was observed that Mo recovered powders (see Figure 8) had a very similar shape and size with respect to the commercial ${ }^{100} \mathrm{Mo}$-enriched powders (99.05\% isotopic enrichment) of Isoflex (San Francisco, CA, USA), shown in Figure 11. This ensures the possibility to use recovered powders for the target preparation also using the SPS technique, as the ${ }^{100}$ Mo-enriched powders of Isoflex have been used (see Figure 10b).
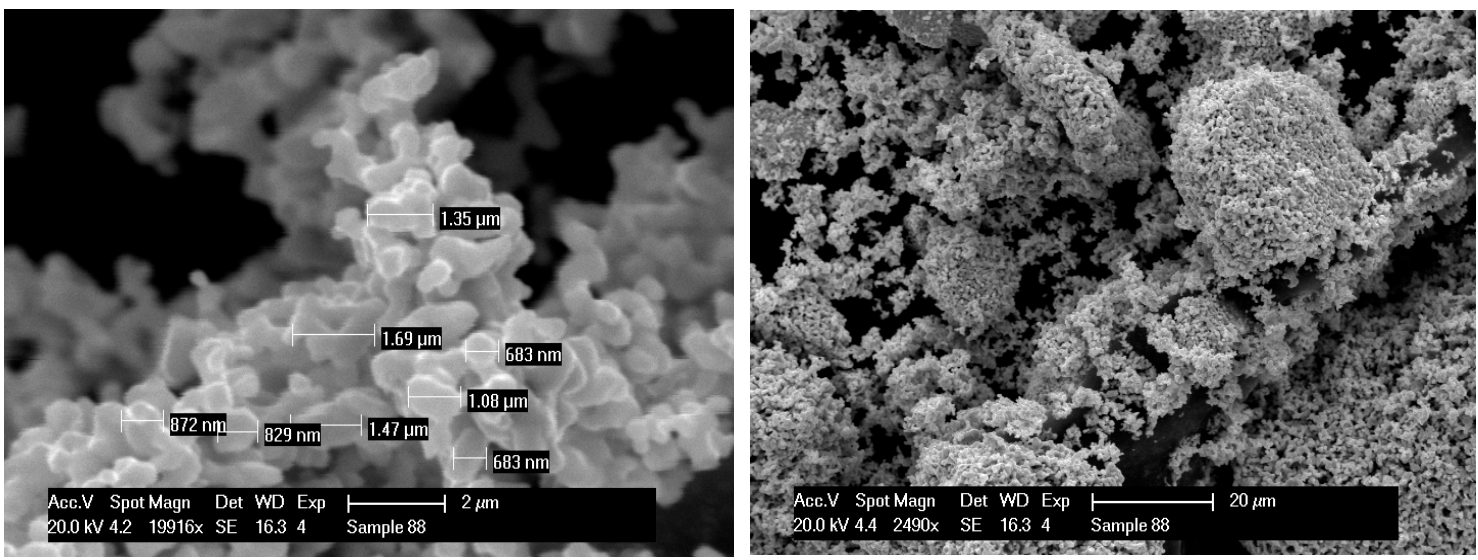

Figure 11. SEM analysis of the ${ }^{100}$ Mo commercial powders of Isoflex (USA).

Since all the Mo recovery tests presented in this work were realized with nonenriched Mo, the further study dedicated to a validation of the proposed methods using enriched Mo powders is essential and is currently in progress. 


\section{Conclusions}

In order to get more attractive from the economic point of view the new, cyclotron-based, ${ }^{99} \mathrm{~m}$ Tc alternative production route, a procedure to close the loop and recover the costly ${ }^{100} \mathrm{Mo}$-enriched starting material from the separation module waste under metallic form was developed. The proposed method allowed to perform the recovery of $\mathrm{MoO}_{3}$ with a $92 \%$ yield.

For the next recovery steps, a reliable method able to provide the reduction of batches of $\mathrm{MoO}_{3}$ up to $1 \mathrm{~g}$, either from the commercial supplier or using the "working" material coming from the separation module has been developed. Reduction yields up to $98 \%$ were achieved with a reduction time no longer than $4 \mathrm{~h}$ ( $+5 \mathrm{~h}$ heating). By increasing the reduction time, it may be possible to improve the transformation to metallic Mo or reduce higher amounts of $\mathrm{MoO}_{3}$ in the same reactor. The overall yield of the two steps higher than $90 \%$ was achieved.

The recovered Mo powders have been successfully used for preparation of the targets by applying HIVIPP technique. Moreover, the powders display size and shape similar to the commercial ${ }^{100}$ Mo-enriched powders available from Isoflex, as evidenced by SEM analyses. Therefore, it can be inferred that the SPS technique can also be adopted to produce the Mo targets using recovered powder.

Author Contributions: The Conceptualization of the Mo reduction system was made by P.B. The Concept of the $\mathrm{MoO}_{3}$ precipitation method by use of nitric acid was proposed by S.C. (Sara Carturan). The Methodology for $\mathrm{MoO}_{3}$ recovery has been developed by H.S. and S.C. (Sara Carturan). The Methodology for $\mathrm{MoO}_{3}$ reduction has been developed by C.R.A. and has been Validated by H.S. and S.C. (Sara Cisternino). Software for the reduction furnace automatic control was realized by C.R.A. Investigation of the content of the starting materials and all the products of recovery experiments was realized by H.S. Resources of the lab for $\mathrm{MoO}_{3}$ recovery experiments have been provided by S.C (Sara Carturan) and J.E. Data Curation was the responsibility of H.S. and C.R.A. The "nat Mo-rich "waste" from the separation module, as the starting material for recovery procedure, has been provided by P.M. and A.B. Original Draft Preparation has been realized by H.S. Writing-Review \& Editing, H.S., S.C. (Sara Cisternino), C.R.A., S.C. (Sara Carturan), J.E., A.B., and P.M. Work on visualization was realized by H.S.; J.E. as a responsible of TECHN-OSP project was in charge of work Supervision, Administration, and Funding Acquisition.

Funding: This research was realized in the framework of TECHN_OSP project funded by CSN5 of the Istituto Nazionale di Fisica Nucleare, Italy for 2015-2017. National responsible: J. Esposito, INFN-LNL.

Acknowledgments: Special thanks should be given to A. Zanon and P. Bezzon for electronics and vacuum equipment support of the reduction apparatus. We are grateful to V. Palmieri responsible of the INFN-LNL Laboratories for Surface \& Material Treatments for Nuclear Physics for the access to XRD and SEM. We also appreciate the help of the Mechanical workshop of INFN-LNL.

Conflicts of Interest: The authors declare no conflict of interest.

\section{References}

1. SNMMI Addresses Mo-99 Isotope Shortage-SNMMI. Available online: http://www.snmmi.org/ NewsPublications/NewsDetail.aspx?ItemNumber=30394 (accessed on 10 February 2019).

2. International Atomic Energy Agency. Feasibility of Producing Molybdenum-99 on a Small Scale Using Fission of Low Enriched Uranium or Neutron Activation of Natural Molybdenum; International Atomic Energy Agency: Vienna, Austria, 2015; ISBN 978-92-0-114713-4.

3. IAEA. Cyclotron Based Production of Technetium-99m; IAEA: Vienna, Austria, 2017; ISBN 978-92-0-102916-4.

4. Martini, P.; Boschi, A.; Cicoria, G.; Zagni, F.; Corazza, A.; Uccelli, L.; Pasquali, M.; Pupillo, G.; Marengo, M.; Loriggiola, M.; et al. In-house cyclotron production of high-purity Tc-99m and Tc-99m radiopharmaceuticals. Appl. Radiat. Isot. 2018, 139, 325-331. [CrossRef]

5. Gagnon, K.; Bénard, F.; Kovacs, M.; Ruth, T.J.; Schaffer, P.; Wilson, J.S.; McQuarrie, S.A. Cyclotron production of $99 \mathrm{mTc}$ : Experimental measurement of the $100 \mathrm{Mo}(\mathrm{p}, \mathrm{x}) 99 \mathrm{Mo}, 99 \mathrm{mTc}$ and $99 \mathrm{gTc}$ excitation functions from 8 to $18 \mathrm{MeV}$. Nucl. Med. Biol. 2011, 38, 907-916. [CrossRef] [PubMed]

6. Benard, F.; Buckley, K.R.; Ruth, T.J.; Zeisler, S.K.; Klug, J.; Hanemaayer, V.; Vuckovic, M.; Hou, X.; Celler, A.; Appiah, J.-P.; et al. Implementation of Multi-Curie Production of $99 \mathrm{mTc}$ by Conventional Medical Cyclotrons. J. Nucl. Med. 2014, 55, 1017-1022. [CrossRef] [PubMed] 
7. Schaffer, P.; Bénard, F.; Bernstein, A.; Buckley, K.; Celler, A.; Cockburn, N.; Corsaut, J.; Dodd, M.; Economou, C.; Eriksson, T. Direct Production of 99m Tc via 100 Mo (p, 2n) on Small Medical Cyclotrons. Phys. Procedia 2015, 66, 383-395. [CrossRef]

8. Sodium Pertechnetate (99mTc) Injection (Accelerator produced) Monograph No. 2891. January 2018: 2891. Volume 9.3, World Health Organization: Geneva, Switzerland, 2018; European Pharmacopoeia 9.3. 4801-4803.

9. Andersson, J.D.; Thomas, B.; Selivanova, S.V.; Berthelette, E.; Wilson, J.S.; McEwan, A.J.B.; Gagnon, K. Robust high-yield $\sim 1$ TBq production of cyclotron based sodium [99mTc]pertechnetate. Nucl. Med. Biol. 2018, 60, 63-70. [CrossRef] [PubMed]

10. Esposito, J.; Vecchi, G.; Pupillo, G.; Taibi, A.; Uccelli, L.; Boschi, A.; Gambaccini, M. Evaluation of Mo99 and Tc 99m Productions Based on a High-Performance Cyclotron. Sci. Technol. Nucl. Ins. 2013, 2013, 1-14.

11. Boschi, A.; Martini, P.; Pasquali, M.; Uccelli, L. Recent achievements in Tc-99m radiopharmaceutical direct production by medical cyclotrons. Drug Dev. Ind. Pharm. 2017, 43, 1402-1412. [CrossRef]

12. Martini, P.; Boschi, A.; Cicoria, G.; Uccelli, L.; Pasquali, M.; Duatti, A.; Pupillo, G.; Marengo, M.; Loriggiola, M.; Esposito, J. A solvent-extraction module for cyclotron production of high-purity technetium99m. Appl. Radiat. Isot. 2016, 118, 302-307. [CrossRef]

13. Skliarova, H.; Cisternino, S.; Cicoria, G.; Marengo, M.; Palmieri, V. Innovative Target for Production of Technetium-99m by Biomedical Cyclotron. Molecules 2019, 24, 25. [CrossRef]

14. Palmieri, V.; Skliarova, H.; Cisternino, S.; Marengo, M.; Cicoria, G. Method for Obtaining a Solid Target for Radiopharmaceuticals Production. International patent application PCT/IB2018/056826, 7 September 2018. National Institute of Nuclear Physics, deposition reference P1183PC00.

15. Sugai, I. An application of a new type deposition method to nuclear target preparation. NIM A 1997, 397, 81-90. [CrossRef]

16. Uzunov, N.M.; Melendez-Alafort, L.; Bello, M.; Cicoria, G.; Zagni, F.; De Nardo, L.; Selva, A.; Mou, L.; Rossi-Alvarez, C.; Pupillo, G.; et al. Radioisotopic purity and imaging properties of cyclotron-produced ${ }^{99 \mathrm{~m}}$ Tc using direct ${ }^{100} \operatorname{Mo}(p, 2 n)$ reaction. Phys. Med. Biol. 2018, 63, 185021. [CrossRef] [PubMed]

17. Gumiela, M. Cyclotron production of 99m Tc. Nucl. Med. Biol. 2018, 58, 33-41. [CrossRef] [PubMed]

18. Park, K.H.; Reddy, B.R.; Mohapatra, D.; Nam, C.-W. Hydrometallurgical processing and recovery of molybdenum trioxide from spent catalyst. Int. J. Miner. Process. 2006, 80, 261-265. [CrossRef]

19. Kar, B.B.; Datta, P.; Misra, V.N. Spent catalyst: secondary source for molybdenum recovery. Hydrometallurgy 2004, 72, 87-92. [CrossRef]

20. Gagnon, K.; Wilson, J.S.; Holt, C.M.B.; Abrams, D.N.; McEwan, A.J.B.; Mitlin, D.; McQuarrie, S.A. Cyclotron production of 99mTc: Recycling of enriched 100Mo metal targets. Appl. Radiat. Isot. 2012, 70, 1685-1690. [CrossRef] [PubMed]

21. Statham, P.J. Limitations to Accuracy in Extracting Characteristic Line Intensities From X-Ray Spectra. J. Res. Natl. Inst. Stand. Technol. 2002, 107, 531-546. [CrossRef] [PubMed]

22. Arnoldy, P.; de Jonge, J.C.M.; Moulijn, J.A. Temperature-Programmed Reduction of $\mathrm{MoO}_{3}$, and $\mathrm{MoO}_{2}$. J. Phys. Chem. 1985, 89, 4517-4527. [CrossRef]

23. Ferris, L.M. Solubility of Molybdic Oxide and Its Hydrates in Nitric Acid, Nitric Acid-Ferric Nitrate, and Nitric Acid-Uranyl Nitrate Solutions. J. Chem. Eng. Data 1961, 6, 600-603. [CrossRef]

24. Pak, J.-J.; Jo, J.-O.; Park, C.-H.; Kang, J.-G.; Shin, D.-H. Recovery of Molybdenum from Spent Acid by Ammonia Gas Neutralization. Mater. Trans. 2008, 49, 202-207. [CrossRef]

25. Schulmeyer, W.V.; Ortner, H.M. Mechanisms of the hydrogen reduction of molybdenum oxides. Int. J. Refract. Metals Hard Mater. 2002, 20, 261-269. [CrossRef]

26. Kim, B.-S.; Kim, E.; Jeon, H.-S.; Lee, H.-I.; Lee, J.-C. Study on the Reduction of Molybdenum Dioxide by Hydrogen. Mater. Trans. 2008, 49, 2147-2152. [CrossRef]

27. Gupta, C.K. Extractive Metallurgy of Molybdenum; CRC Press: Boca Raton, FL, USA, 1992; ISBN 978-0-84934758-0.

(C) 2019 by the authors. Licensee MDPI, Basel, Switzerland. This article is an open access article distributed under the terms and conditions of the Creative Commons Attribution (CC BY) license (http:/ / creativecommons.org/licenses/by/4.0/). 